\title{
MUDANÇAS SOCIAIS E MAL-ESTAR DOCENTE: ESCOLA, PASSADO E PRESENTE E NOVAS EXIGÊNCIAS PARA OS PROFESSORES E PROFESSORAS
}

\author{
Adenir Carvalho Rodrigues ${ }^{1}$ \\ Jerônimo Jorge Cavalcante Silva ${ }^{2}$ \\ Nilcelio Sacramento Sousa ${ }^{3}$
}

\begin{abstract}
Resumo: As transformações sociais, políticas e econômicas mudam, substancialmente, as concepções e os paradigmas educacionais, alterando, com isso, a visão e o valor que dados aos agentes centrais do processo educativo. Este estudo teve como objetivo conhecer o processo de mudança que afeta os sistemas escolares a partir das várias reformas empreendidas e das consequências para a imagem, valores sociais e profissionais dos professores, enfatizando o conceito e as exigências de formação continuada. A metodologia utilizada contou com a pesquisa bibliográfica com uso de referenciais teóricos fundamentais para sustentar as discussões. As mudanças sociais vêm imprimindo à escola exigências e responsabilidades as quais sobrecarregaram os professores de várias formas, fazendo aparecer o mal-estar docente, causando desconforto aos profissionais da educação, exigindo novas competências e reflexões no campo da profissionalização.
\end{abstract}

Palavras-chave: Escola e mudanças sociais. Mal-estar docente. Formação continuada docente.

\section{SOCIAL CHANGE AND MALTING TEACHER: SCHOOL, PAST AND PRESENT AND NEW REQUIREMENTS FOR PRODESSORS}

\begin{abstract}
Social, political, and economic transformations substantially change educational conceptions and paradigms, thereby changing the vision and value that is given to the central actors of the educational process. This study aimed to know the process of change that affects school systems from the various reforms undertaken and the consequences for the image, social and professional values of teachers, emphasizing the concept and requirements of continuing education. The methodology used relied on bibliographical research with the use of fundamental theoretical references to support the discussions. Social changes have imposed on the school demands and responsibilities that have overwhelmed teachers in various ways, causing teacher malaise to appear, causing discomfort to the education professionals, requiring new skills and reflections in the professionalization field.
\end{abstract}

Keywords: School and social changes. Teacher malaise. Continuing education teacher.

\section{INTRODUÇÃO}

Por sermos seres históricos, nossos pensamentos e ações mudam ao longo do tempo, a partir do enfrentamento das condições materiais e espirituais da existência, seja no universo individual, seja no coletivo. É assim que produzimos a nós mesmos e a cultura. Vamos, ao longo do tempo, assimilando, transformando, criando e recriando a partir da herança cultural recebida e, por meio dela, empreendendo novos projetos de

\footnotetext{
${ }^{1}$ Mestre em Educação e Diversidade pela Universidade do Estado da Bahia - UNEB Campus IV(2016).

${ }^{2}$ Graduado em Economia pela Universidade Federal da Bahia. Mestre em Educação pela Universidade Portucalense, Portugal. Mestre e Doutor em Educação pela Universidade Autônoma de Barcelona. Pós-Doutor em Educação pela Universidade de Cádiz, Espanha.

${ }^{3}$ Mestre em educação e diversidade pela Universidade do Estado da Bahia, ESPECIALISTA em Gestão, Coordenação e Orientação Educacional pela Faculdade Católica de Ciências Educacionais da Bahia (2010). Possui graduação em PEDAGOGIA - Universidade do Estado da Bahia (2008) e CIÊNCIAS NATURAIS (2012) pela Universidade Federal do Vale do São Francisco - UNIVASF (Universidade Aberta do Brasil).
} 
mudanças capazes de fazer com que sobrevivamos às próprias exigências criadas por nós a partir da interação com o meio e com as intersubjetividades. Reafirmamos nossa condição humana nessa interação mútua, sempre sujeita a rupturas e continuidades. Para Aranha (2006, p. 19), "não nos compreendemos fora da nossa prática social, porque esta, por sua vez, se encontra mergulhada em um contexto histórico-social concreto”. São nas ações concretas que nós criamos e aperfeiçoamos nossos instrumentos de trabalho, criamos as instituições sociais, e nestas e, por meio destas, os modelos de comportamento, regras, valores e todos os tipos de saberes historicamente construídos.

A educação é a maneira pela qual a humanidade encontrou para fazer com que o conhecimento seja transmitido de uma geração à outra, mantendo vivas as formas de comportamentos valorizados (ou suprimindo os valores considerados inferiores) e o aperfeiçoamento das atividades responsáveis pela produção da existência. É por meio dela que a memória de um povo permanece viva e dá as condições da sobrevivência material e espiritual. Ela é fundamental para a socialização e humanização do ser humano. Segundo Aranha (1996, p. 18), "trata-se de um processo que dura a vida toda e não se restringe à mera continuidade da tradição, pois supõe a possibilidade de rupturas, pelas quais a cultura se renova e o homem faz e refaz a história”.

Como podemos perceber, a educação é inerente à humanidade e se configura como condição de humanização, não apenas pelos processos conscientes e sistematizados de transmissão dos conhecimentos, mas também, e talvez bem mais, pelas formas inconscientes de interação entre os membros de um grupo, por representar um modo de vida, em que um aprende com o outro de forma espontânea e involuntária, ou pelo simples desejo de viver e sobreviver às intempéries do mundo físico e às exigências coercitivas impostas pelo universo social.

Para Brandão (1981):

A educação existe onde não há a escola e por toda parte podem haver redes e estruturas sociais de transferência de saber de uma geração a outra, onde ainda não foi sequer criada a sombra de algum modelo de ensino formal e centralizado. Porque a educação aprende com o homem a continuar o trabalho da vida. A vida que transporta de uma espécie para a outra, dentro história da natureza, e de uma geração a outra de viventes, dentro da história das espécies, os princípios através dos quais a própria vida aprende e ensina a sobreviver e a evolui em cada tipo de ser (BRANDÃO, 1981, p. 13).

A educação como processo de aprender e ensinar acontece em todos os espaços e se configura como uma das características mais natural da humanidade, como afirma 
o autor: "a educação aprende com o homem a continuar o trabalho da vida". Todavia, ela representa o ponto de humanização mais necessário, em que o ser humano aprende com a educação e a educação projeta sua autoimagem no devir construindo as representações de mundo, os símbolos, os valores, as formas de trabalho e toda teia de significados inerente ao universo antropológico. Sem a educação em sentido amplo, não se pode pensar em evolução, em socialização e, consequentemente, em humanização.

Como a educação é a expressão mais autêntica de socialização, em que os seres humanos aprendem e ensinam, e, por meio dessa interação e troca, criam as mais variadas formas de representação para estar e sentir-se no mundo, adaptando-o, modificando-o e projetando novas formas de viver neste mundo num devir permanente. É nesse sentido que corroboramos com Aranha (1996, p. 50), quando afirma que "a educação não é, porém, a simples transmissão da herança dos antepassados, mas o processo pelo qual também se torna possível a gestação do novo e ruptura com o velho".

Assim é a educação, expressão legítima da própria humanidade, que muda com ela ou é o motor da própria mudança. Nesse contexto, de educação em sentido amplo, nos referimos primeiramente à educação informal, mas também entraremos na discussão da educação formal ou institucionalizada, sendo esta a que nos interessa refletir mais pontualmente dentro do processo de mudanças sociais que vem ocasionado o mal-estar docente.

Portanto, o contexto atual da educação formal ou institucionalizada é fruto de longo processo histórico marcado por tensões e interesses. Sendo assim, em cada sociedade, as transformações sociais, políticas e econômicas mudam substancialmente as concepções e os paradigmas educacionais, assim como também têm acompanhado esta mudança a visão e o valor que se dá aos agentes centrais do processo educativo, que são eles: a escola, os alunos, os saberes e os professores.

Desta forma, as mudanças sociais vêm imprimindo à escola exigências e responsabilidades as quais sobrecarregaram os professores de várias formas. Mudanças estas que fizeram aparecer o mal-estar docente, causando desconforto aos profissionais da educação, por exigir novos saberes fazeres que requerem reflexões importantes no campo da formação e, consequentemente, da profissionalização. Portanto, a formação continuada precisa ser pensada levando em consideração o contexto em que a escola está situada hoje.

Neste texto, demos ênfase ao conhecimento sobre o processo de mudança que afeta os sistemas escolares, a partir das várias reformas empreendidas e das 
consequências para a imagem, valores sociais e profissionais dos professores, enfatizando o conceito, a evolução e as exigências dos processos formativos, com destaque para a formação continuada, dado a crescente necessidade de pensar e repensar os processos formativos, em que estes sejam capazes de acompanhar as mudanças sofridas pela sociedade, o que tem afetado consubstancialmente a escola e seus partícipes.

Para a construção do texto, a metodologia utilizada contou com a pesquisa bibliográfica por meio da análise de referenciais teóricos fundamentais para sustentar as discussões sobre Educação, concepções e evolução histórica e sobre o mal-estar docente e as novas exigências para a escola e para os professores. A partir das contribuições das discussões levantadas por autores como: Aranha, Bauman, Brandão, Canário, Cortesão, Esteve, Nóvoa, entre outros.

Dentro desse contexto de mudanças pelas quais vivem as sociedades, os quais envolvem diretamente a escola e todos que fazem parte dela, apontamos com maior ênfase a situação atual do professor, pois sobre ele recai grande parte dos problemas que acometem para a escolarização atual. Esses problemas afetam diretamente a identidade profissional do professor, o que tem ocasionado, como já dito anteriormente, o mal-estar docente.

Diante de tudo que envolve esse mal-estar, temos consciência que as mudanças da atual conjuntura educacional exigem posturas, estratégias e ações complexas, amplas e variadas. A formação continuada precisa trazer para a discussão os elementos que envolvem os saberes e os fazeres dos professores, sem isso, dificilmente, as mudanças ocorrerão e, mais uma vez, o professor será o bode expiatório do conjunto de reformas que se empreende e se pretende empreender na educação, sem o devido sucesso que se esperava.

\section{EDUCAÇÃO, CONCEPÇÕES E EVOLUÇÃO HISTÓRICA}

A primeira forma de educação se dá pelo processo inicial de socialização, pois, desde que nascemos, somos submetidos a um rigoroso sistema de aprendizagens que só termina com a morte. Esse processo acontece de forma não sistematizada ou mesmo inconsciente e de forma espontânea. Esse tipo de educação é empírica, casual e exercida a partir das vivências e com base no bom senso e na sobrevivência da espécie. Acontece pela apreensão de aprendizagens e comportamento exterior, que, em seguida, é 
interiorizada pelo indivíduo, tornando-se um comportamento apreendido e novamente repassado a outros membros do grupo. Essa é a educação informal, que, por não ser organizada e sistematizada com a finalidade de ensinar, muito embora, em muitas situações se tenha a intenção de ensinar um comportamento, mas o mesmo não é feito de forma intencional e sistematizada, usando, para isso, os instrumentos certos que facilitem a aprendizagem.

Já a educação formal tem, como princípio básico, a intencionalidade. Por isso, é sistematizada e institucionalizada com a finalidade de ensinar usando um corpus de conteúdo eleito para este fim, que se presta a atender às necessidades de uma dada sociedade. Ela se organiza por um conjunto de método ou técnicas com profissionais destinando a este fim. Além do mais, institui-se um local que se destina exclusivamente a esta tarefa, esse lugar é a escola, que, desde o seu nascimento, passa a ser a forma hegemônica do processo de transmissão sistematizada e oficializada dos conhecimentos das sociedades e das suas respectivas culturas.

A educação em qualquer sentido, informal e formal, pressupõe o ato de educar, que, em latim, se escreve educare, e significa conduzir de um estado a outro, é modificar numa certa direção o que é suscetível de educação, de aprendizagem de transmissão e ressignificação. Para Aranha (1996), o ato pedagógico pode ser definido como uma atividade sistemática de interação entre seres sociais, tanto no nível intrapessoal como na interação com o meio, uma ação exercida sobre o sujeito ou grupos de sujeitos, visando provocar mudanças tão eficazes que os tornem elementos ativos da própria ação exercida. Dessa forma, pressupõe a interligação no ato pedagógico de três componentes: um agente, que pode ser uma pessoa, um grupo de pessoas ou o meio social; uma mensagem transmitida, que pode ser um conteúdo, uma informação, um método, habilidade etc. E, por último, um educando, que pode ser um aluno, um grupo de pessoas ou uma geração.

Esses elementos do ato pedagógico configuram o cerne do processo educativo e ambos estão sujeitos às mudanças sociais. $\mathrm{O}$ agente é o resultado das interações sociais e ambientais determinado pelos contextos históricos em que está inserido, bem como imbricado nas relações de poder que vão estabelecendo sua atuação no mundo. A mensagem é contextual, fruto das produções da linguagem, da ciência, da técnica e de todo tipo de saberes construído, reconstruído e ressignificado pelos agentes sociais e, por último, o educando ou sujeito a ser educado; seja um indivíduo, seja um grupo, este é sempre o que se espera do ser individual a ser inserido na sociedade como membro 
dela, que precisa se adequar (ou contestar) às normas, aos valores e a desenvolver determinados comportamentos aceitos e valorizados para a continuidade e manutenção da sociedade pretendida.

A educação, como já mencionamos, atravessa a vida dos indivíduos do nascimento à morte, bem como a função de educar não está restrita a uma pessoa, mas a várias instâncias, à família, à igreja, ao trabalho, ao lazer, aos meios de comunicação, às várias interações com o meio social mais amplo, com meio físico e consigo mesmo. Porém, à medida que as sociedades foram se tornando mais complexas, com o acúmulo de excedentes da produção e com a divisão de tarefas, ocorre alteração na estrutura social, gerando as divisões sociais e, consequentemente, mudando as relações de poder. Essa mudança faz nascer ricos e pobres, e o saber passa a ser moeda de privilégios, nascendo, nesse contexto, a escola como instrumento de transmissão do saber acumulado, porém restrito a poucos.

Essa divisão social e das formas e maneiras de saber é fundamental para entender em que contexto a escola surge e a partir de que alicerces se desenvolve para tornar-se a maneira exclusiva de sistematização das formas de ensinar e aprender. Dessa forma, Brandão nos ajuda a compreender que a escola aparece na história como a responsável pela divisão, especialização e hierarquização do saber, pois que:

Então é começo de quando a sociedade separa e aos poucos opõe: o que faz, o que se sabe com o que se faz e o que se faz com o que se sabe. Então é quando, entre outras categorias de especialista sociais, aparecem as de saber e de ensinar a saber. Este é o começo do momento em que a educação vira o ensino, que inventa a pedagogia, reduz a aldeia à escola e transforma "todos" em educador (BRANDÃO, 1981, p. 27, 32).

O que se nota é que a escola, atualmente, se transformou na responsável pela formação integral do educando e na detentora de praticamente todos os processos ligados ao ato educativo e a seus agentes. Mas o que nos conta Aranha (1996) é que, na Antiguidade e Idade Média, a escola exercia influência partilhada com a família, cuja escola estava mais restrita à instrução que à formação integral do aluno. Portanto, a escola não constituía um mecanismo de ação educacional preponderante. Assim, continua a autora (1996, p. 72): “a instituição escolar não existiu sempre, e sua natureza e importância variaram no tempo, dependendo das necessidades socioeconômicas dos grupos em que esteve inserida". Assim como do tipo de ser humano e de sociedade que começou a se idealizar, sendo a escola a partir de dado momento a responsável por essa tarefa de criação de um modelo de homem para uma dada sociedade a se desenvolver plenamente. 
Como vimos, a escola surge muito antigamente, junto com os processos sociais de divisão de tarefas, com a especialização dos saberes e hierarquização desses saberes para conquista, manutenção e ampliação de poderes. Porém, a escola institucionalizada como conhecemos hoje é uma criação burguesa do século XVI. A partir desse momento histórico e seguindo em direção ao século XVII e XVIII, a escola passa a ter essa finalidade, a de disciplinar e formar um novo homem para uma nova sociedade, além de apresentar outras características e funções que, nesse período, deu a ela o status de reprodutora de privilégios e uma das instituições legitimadora da desigualdade social.

Com o advento da Revolução Industrial iniciada no século XVIII, altera alguns aspectos da exigência da escola burguesa, entre elas, a formação acadêmica predominantemente humanística, se contrapõe à necessidade de formação técnica especializada, bem como aos estudos de ciências.

Essa mudança e atenção dada aos novos conteúdos sugerem o pleno triunfo da burguesia capitalista e do desenvolvimento e consolidação da ciência, que adentra o século XIX, com o objetivo de laicizar a educação, torná-la pública e gratuita, já que até o momento não era e se configurava como privilégio de poucos. Aranha (1996) chama atenção para o fato de que, no século XIX, os países desenvolvidos conseguiram a universalização do ensino básico, enquanto, no Brasil, nem no século XX, conseguiu-se superar as dificuldades de acesso à escola.

De maneira geral, a escola do século XIX no Brasil foi marcada pela presença da elite com um ensino secundarista propedêutico que preparava os ricos para o nível superior e a instrução primária não consegue sair para além das poucas legislações e garantir, de fato, o acesso à população menos favorecida.

Como sabemos, a história da educação no Brasil é extensa e careceria de muito tempo para debatê-la. No entanto, o que se pretende, aqui, é mostrar como a escola se insere dentro do contexto das transformações sociais, afetando e sendo afetada por estas.

$\mathrm{O}$ século XX foi marcado por transformações cruciais em todos os segmentos: social, político, econômico e cultural, além de ser introduzido na sociedade da informação. Tivemos forte elaboração teórica, mesmo que sobre a influência de correntes pedagógicas europeias e norte-americanas, mas contamos também com reflexões originais que trouxeram para o centro nosso contexto histórico e a busca de resolução dos desafios e das dificuldades próprias de um país periférico como o nosso.

O século XXI é herdeiro das mudanças iniciadas no século XX, ampliadas nesse início de século, o que caracteriza uma sociedade em transição, que se depara com as 
mudanças em todos os setores cada vez mais aceleradas e móveis. Vivemos, atualmente, o que muitos teóricos denominam de pós-modernidade. Embora não seja o nosso objetivo debater essa categoria, mas defini-la resumidamente, faz-se importante para entendermos em que contexto está inserida a escola do presente, bem como as exigências que a ela é posta pela sociedade, que tem responsabilizado a escola, e com ela seus agentes, em especial, o professor, que vive numa encruzilhada pelas cobranças por resultados positivos em favor desta sociedade e de um tipo de ser humano que se adapte a ela. Se é que essa sociedade em plena e acelerada transformação tem um projeto bem delimitado como já se teve no passado, quando o ritmo das mudanças era bem mais lento. Mas, de uma forma ou de outra, as mudanças estão em curso e as exigências por uma escola que atenda a ela também.

Para definirmos o paradigma da pós-modernidade e compreendermos o que ele significa em linhas gerais, é necessário elencarmos o que caracterizou, então, a modernidade. Didaticamente, a história costuma marcar como início da Idade Moderna o século XVII, marcado na Filosofia pelas ideias de René Descartes, Francis Bacon e Locke, entre outros. Nas ciências, Galileu, Kleber e Newton, que possibilitaram a inauguração de uma nova racionalidade humana, desenvolvendo o método científico e a ideia da supremacia na razão humana. Supremacia que fora intensificada com o advento do Iluminismo no século XVIII, o qual transforma a razão humana como instrumento capaz de chegar ao conhecimento e como orientadora de toda a ação. Assim, só por meio da razão, o ser humano conseguiria chegar ao que Kant chamou de maioridade do espírito humano, o que resume a pretensão humana em favor de sua racionalidade, a qual será racionalidade teórica e razão prática que propicia, amplia e desenvolve as modernas tecnologias.

Essa racionalidade intensificada pelo iluminismo se configurou em vários aspectos, com ênfase no reconhecimento da subjetividade humana. Sobre eles, Aranha (2006) sistematiza e os apresenta como:

1. Valorização da subjetividade, garantia da autonomia do sujeito, tolerância religiosa, ética laica.

2. Valorização da ciência como modelo privilegiado de conhecimento, que resultou no desenvolvimento da tecnologia; pretendia-se, assim, expulsar as crendices, superstições, e cumprir o prognóstico de Bacon "Saber é poder"; o corolário do binômio ciência-técnica é o progresso, expressão das promessas da modernidade.

3. Elaboração do conceito de Estado representativo, sustentado nas noções de cidadania e participação, em oposição ao absolutismo dos reis; essas ideias frutificaram no anseio de liberdade e igualdade, metas da democracia. 
4. Oposição ao arbítrio e exigência de um estado de direitos - porque fundados em leis -, cuja expansão busca a garantia dos direitos humanos.

5. Economia de mercado, livre de entraves com o modelo liberal (ARANHA, 2006, p. 359).

Olhando pela indicação dos aspectos que caracterizaram a modernidade, podemos concluir, com ajuda da autora, inclusive, que a pós-modernidade, mesmo sem consenso entre os teóricos que a define, que a mesma representa a tentativa de interpretação e de superação da crise instalada pela modernidade. Pois, remetendo à história, a modernidade foi um projeto que não se concretizou, justamente por levar a crise à sociedade e a suas principais instituições, a saber: o Estado-nação, a família e a escola.

As conquistas da modernidade que chegam ao século XXI se apresentam, hoje, sob a forma de inovação, do domínio da tecnologia da informação, do domínio da razão instrumental, aquela que recorremos para determinar o que fazer e como fazer sobre a razão vital, que determina as relações humanas afetivas para a sobrevivência de valores que coloquem a vida no centro de toda existência. Esses valores construídos na modernidade, de que somos herdeiros, ameaçam a própria vida e nos colocam diante de paradoxos difíceis de resolver. De um lado, o homem busca o desenvolvimento desenfreado por meio do domínio da natureza, o que deveria ser meio e instrumento, passa a ser princípio e fim. E, do outro lado, ameaça a própria existência humana, em decorrências das inovações e progressos.

No presente, vivenciamos a sociedade da informação que muda as relações entre os seres humanos, volatilizando e tornando-as mais efêmeras, na mesma velocidade com que as informações chegam e vão embora, sem, às vezes, serem absorvidas, interpretadas e assimiladas, cedendo lugar a outra gama de informações e novidades que nos deixam atordoados e, muitas vezes, paralisados. Essas mudanças impressas e impostas de forma rápida, desde o surgimento do computador e da internet, vêm criando novas e variadas formas de comunicação com alto uso de imagens, sons e mídias.

Essa e tantas outras mudanças que a sociedade atual vivencia adentraram a escola e mudaram sua face mais tradicional, exigindo novas posturas, tanto no que se refere aos conteúdos da aprendizagem, à relação entre seus agentes, professor, aluno e, principalmente, sobre qual seria o seu papel dentro desse contexto de mudanças de paradigmas, já que a invenção de novos se faz tão urgente e fluído ao mesmo tempo. Não temos a garantia e nem podemos assegurar que um modelo seja o ideal (se é que 
um dia tivemos modelo ideal/real), para garantir o sucesso do educando dentro de uma conjuntura social de culturas que presencia uma fluidez nunca vista antes.

Nesse aspecto, nos referimos ao que Bauman (2013, p. 23) denominou de mundo líquido moderno, em que "a modernidade líquida é uma civilização do excesso, da redundância, do dejeto e do seu descarte”. Nessa direção, é compreensível que o mundo o qual se conheceu não existe mais, o que era antes, hoje, não é mais e, dessa forma, as mudanças são repentinas e nos levarão rumo ao desconhecido, ao efêmero e ao descartável. Nesse modo de viver contemporâneo, em que as identidades são plásticas e instáveis, as relações se encontram também estremecidas e a escola recebe e tem que lidar com todas essas questões e ainda é cobrada a dar respostas, como a única responsável por reverter o curso desenfreado da história.

Mas o que se questiona é o porquê de a escola ter se tornado a única forma de educação valorizada, chamando para si tarefas que antes pertenciam à família e a outras instâncias educadoras e socializadoras de variados conhecimentos e saberes. Canário (2006) nos chama atenção para o fato de que a escola vive atualmente uma situação contraditória e paradoxal, já que as promessas iniciadas com o Iluminismo que identificava ou associava escola, razão e progresso não se cumpriram. A escola que era a depositária de todo esse projeto, motivo pelo qual chama para si a responsabilidade de instrumentalizar os seres humanos por meio da razão, fracassa ou não atinge seu fim, como pretendiam os teóricos do iluminismo. Nesse contexto, ela passa da euforia ao desencanto e, nesse ponto, o paradoxo se acentua, já que todo o projeto da modernidade do qual somos herdeiros não conseguiu resolver os impasses de ordem social e ambiental. Além do mais, há um desequilíbrio entre conhecimento científico e técnico, ambos convivem com a imaturidade social e política e não conseguem resolver as consequências nocivas do progresso.

Nessa direção, Canário (2006) é enfático ao afirmar que esta forma escolar de conceber o processo de aprender foi, passo a passo e com intenção ideológica, se tornando a única forma de conceber a educação e que teve duas consequências fundamentais: conceber o monopólio quase que exclusivo à escola da ação educativa, desvalorizando os saberes adquiridos de forma não escolar; e, por outro lado, contaminou todas as outras formas de educação não escolar a sua imagem e semelhança. Segundo o autor, isso teve como consequência um empobrecimento do campo e do pensamento educativos, que privou a própria escola de buscar referenciais exteriores que lhes permitisse criticar-se e se transformar. 
Portanto, Canário (2006) faz um balanço da educação no século XX e conclui que é

\begin{abstract}
Quase inevitável um balanço da educação escolar, na medida em que a instituição escolar foi progressivamente tornando-se o único ponto de referência de toda a ação educativa. A partir daí, o século XX é marcado por três fatores principais: por um lado, a hegemonia da forma escolar; por outro lado, a naturalização e a persistência da configuração organizacional do estabelecimento de ensino; por último, as mutações sofridas pela instituição escolar, que passou, sucessivamente, de uma modelo de certezas para um modelo de promessas e, finalmente, um terceiro, marcado pela incerteza (CANÁRIO, 2006, p. 13).
\end{abstract}

Procuramos tecer acerca da sociedade, suas mudanças sociais, políticas, econômicas e culturais, justificando o momento em que a escola nasce e se desenvolve, até tomar a dimensão que possui hoje, como única responsável pela ação educativa do ser humano. Brandão (1981) nos ajuda a entender que a educação e, portanto, a escola, é uma exigência social de formação de tipos concretos de pessoas na e para a sociedade. "O que ocorre é que ela é inevitavelmente uma prática social que, por meio da inculcação de tipos de saber, reproduz tipos de sujeitos sociais" Brandão (1981, p. 71). Nesse sentido, sendo uma prática social, ela não escapa aos desígnios dos interesses políticos e econômicos e se tece dentro da teia das relações de poder entre os humanos.

\title{
MAL-ESTAR DOCENTE: NOVAS EXIGÊNCIAS PARA A ESCOLA E PARA OS PROFESSORES
}

O cenário de mudanças atuais entre tantas consequências traz: a emergência de qualificação, acréscimo de desigualdade, desemprego estrutural de massas, precariedade do trabalho e desvalorização dos diplomas escolares, levando a escola a perder suas funções de certezas que era gerar cidadãos bem-sucedidos para ascenderem socialmente. Além desses elementos, a escola convive, atualmente, com muitos desafios. Não basta o acesso, é necessário assegurar permanência, qualidade e condições sociais de competitividade. Enfim, o que se coloca é a incerteza diante do cumprimento por parte dos sistemas educacionais do sucesso e adaptação do ser humano em um mundo cada vez mais mutante, incerto e inseguro para as gerações do presente e mais fortemente para as futuras gerações.

Esse cenário desanimador nos coloca alerta pela realidade dura e sem muitas perspectivas de melhora diante das mudanças sociais e suposta inércia de alteração 
desse quadro, tornando-o cada vez mais grave. Todavia, apesar deste quadro, Nóvoa (1999) nos chama atenção para o fato de que, mesmo diante desse cenário, a escola é o local onde se concentra hoje o maior número de pessoas altamente qualificadas e relativamente protegidas dos confrontos políticos, das competições comerciais e das tentações gestionárias. Dessa forma, acredita que seja justamente na escola que esteja a possibilidade para pensar o futuro.

É justamente nesse ponto que entramos, pois coloca os docentes em sua situação desafiadora. Já que somos considerados qualificados e de maior número entre todos os profissionais, somos responsabilizados quase que exclusivamente pelas mudanças que se espera na sociedade. Essa situação é, sem dúvida, o que tem ocasionado o mal-estar docente, expressão bastante usada atualmente por vários autores, entre eles Esteve (1999), para resumir o conjunto de reações desajustadas dos professores frente às demandas da educação escolar atual, ocasionadas pela mudança social que alteraram o status da profissão docente, sua imagem social e o valor que a sociedade atribui à própria educação, levando-nos a pensar justamente nas questões que, de forma direta ou indireta, são responsáveis pelas instalações dessas reações desajustadas que têm marcados a profissão docente, fruto desta nova configuração do universo da educação escolar.

Para Esteve (1999) e Cortesão (2011), a passagem de um sistema de ensino de elite para um sistema de ensino de massas aumentou significativamente o número de professores e alunos, e com eles novos problemas qualitativos que exigem uma reflexão profunda. Há uma diferença significativa entre trabalhar com um grupo pequeno e homogeneizado pela seleção que trabalhar com alunos vindos de todas as classes sociais, trazendo consigo seus problemas. Daí a frustração e desencanto da maioria dos professores que não souberam redefinir seu papel diante dessa nova realidade. Há um desajustamento neste momento de incerteza, pela perda de referências culturais provocada pelo choque do devir incerto. Assim, certamente, o sentimento de insegurança que afeta os professores está na origem do ceticismo e da recusa em relação às novas políticas de reformas educativas. Até porque, na sua maioria, elas são impostas de cima para baixo, sem a devida participação de quem vive o cotidiano da escola, os professores e professoras.

Para amenizar este quadro, é preciso atuar simultaneamente em várias frentes: formação inicial, formação continuada, material de apoio, relação (responsabilidade, horário de trabalho, salário e valorização profissional como todo). Como percebemos, as mudanças pelas quais passam a escola atualmente têm ocasionado desajustamentos, 
principalmente nos professores que, segundo Canário (2006), é o reflexo da queda de algumas das crenças fundadoras dos sistemas escolares que, nos últimos 30 anos, aumentou o descontentamento em relação à escola que repercutiu negativamente no modo como é socialmente vista a profissão docente. A escolarização massiva e o crescimento exponencial do número de professores conduziram à desvalorização do seu estatuto profissional. Finalmente, a democratização e a heterogeneidade dos públicos escolares fizeram com que a escola fosse invadida pelos problemas sociais que antes lhe eram estranhos, acarretando problemas aos professores de difícil solução.

Sendo assim, corroborando com Esteve, ele acrescenta:

o mal-estar docente se manifesta em diversas modalidade de desmotivação e absenteísmo , falta de investimento profissional, aumento de doenças ocupacionais, refúgio em posturas defensivas ("construção de estratégias de sobrevivência") e em um sentimento de nostalgia em relação a "pretensos anos dourados" da escola, situada em algum lugar do passado (CANÁRIO, 2006, p. 21,22).

Esses elementos que marcam as condições da profissão docente é, sem dúvida, algo que tem afetado consubstancialmente a autoestima e a autoimagem docente, alterando a relação com a escola, com a sociedade e consigo mesmo. As alterações provocadas pelas mudanças de paradigmas na educação estão atreladas a fatores que promoveram a mudança da sociedade, como já apontamos, e, consequentemente, da escola. Segundo Esteve (1999), as investigações costumam apontar dois grupos de fatores para estudar a pressão e influência da mudança social sobre a função docente. $\mathrm{O}$ primeiro fator, considerado de primeira ordem, é aquele que incide diretamente sobre a ação e prática do professor em sala de aula, alterando as condições de realização do seu trabalho. O segundo refere-se às condições ambientais, ao contexto em que se exerce a docência, e possui ação indireta, afetando a motivação, bem como a implicação do professor para com a sua função. Neste terceiro fator, é possível acrescentar as reflexões tecidas por Cortesão (2011) no sistema educativo português, que se encaixa aqui no Brasil. Assim, ela afirma:

Mas é necessário alertar para o fato de esse "mal-estar" ser, também acompanhado e sublinhado pela crescente agressividade com que alguns meios de comunicação social, certas pessoas e algumas entidades mais responsáveis se referem a esta situação. Trata-se, em geral, de pessoas que se autopromovem a especialistas em educação e que atacam professores, formadores, investigadores e o processo educativo em geral (CORTESÃO, 2011, p. 20-21). 
Como podemos perceber, estes fatores são agravados ainda mais pelas pressões externas, que incidem, diretamente, sobre o trabalho do professor. Não se tem levado em consideração os fatores contextuais, em que os problemas, em sala de aula, são encarados apenas como pertencendo ao universo desta mesma sala e, portanto, atribuição exclusiva do professor, recaindo sobre ele toda a responsabilidade em resolvê-los, gerando desajustamento e impotência. Essa condição influencia a imagem que o professor tem de si, do seu trabalho profissional, já que muitos professores não têm sabido adaptar-se a essas mudanças, nem as autoridades políticas e educativas têm traçado estratégias de ação e adaptação, sobretudo em níveis das formações, inicial e continuada.

A reflexão e, principalmente, o conhecimento aprofundado desses fatores são indispensáveis para uma reforma educativa que se queira realmente efetiva e eficaz. Não é possível pensar melhorias na qualidade do ensino sem analisar as mudanças sociais que afetam todas as instituições sociais, principalmente a escola, que a depender da tendência ideológica tende a responsabilizá-la pela redenção, reprodução ou libertação desta mesma sociedade em mudanças aceleradas.

Não dá para menosprezar o aumento das exigências em relação ao professor, falta de participação efetiva da família e de outras instituições socializadoras, as inovações da informática e das comunicações de massa, a dúvida no valor da educação, as contradições que envolvem a docência e mudanças na forma de conceber o sistema educativo e a valorização social do professor, associado à alteração curricular, à falta de material didático, às péssimas condições de trabalho e ao desrespeito pelo professor em sala, ocasionando fragmentação do seu trabalho, desmotivação e muitas desistências da profissão, ou seja, causando o mal-estar docente. Todos estes aspectos que configuram hoje o universo da escola, e, consequentemente, da docência, devem ser profundamente estudados para que se criem estratégias de ações concretas para o devido resgate do valor da escola, numa perspectiva mais emancipadora dos sujeitos, mais democrática, com redução das desigualdades e injustiças sociais.

Nessa mesma perspectiva, porém, de forma mais enfática, Canário (2006) propõe a construção de uma "outra educação", o que representaria uma saída possível para as dificuldades atuais. Dessa forma, ele

supõe a nossa capacidade de agir em dois sentidos que, já na aparência, são contraditórios. Por um lado, agir no sentido de superar a forma escolar, e, por outro, agir no sentido de reinventar a organização escolar, o que implica um terceiro eixo de ação, o de construir uma nova legitimidade para a educação escolar (CANÁRIO, 2006, p. 17). 
Desde o início do texto, a intenção é tratar da educação em sua forma escolarizada dos percursos trilhados por ela, desde sua origem até os dias atuais. Referimo-nos à escola como a conhecemos hoje, sendo esta uma criação burguesa dos séculos XVI ao XVIII. Hoje, vivemos a crise da escola, bem colocada por Canário (2006), que sinaliza estes três pontos que são orientadores da mudança que a escola precisa, visto que os propósitos pelos quais ela fora criada não se enquadram na atual conjuntura de mudanças acelerada.

O autor propõe superar a forma escolar emergida a partir de uma nova forma de conceber a educação, a qual se inicia com o movimento da educação permanente surgida no início da década de 1970, em que o que está em jogo é o aprender contínuo, o qual se identifica com a própria vida. Nessa direção, aparece como uma nova concepção de educação, a qual tem a forma escolarizada como uma parte pequena do processo educativo, atentando nessa perspectiva para a emergência da pessoa como sujeito da formação e se embasa em três pressupostos principais: "o da continuidade do processo educativo, o da sua diversidade e o da sua globalidade" (CANÁRIO, 2006, p. 18). Assim, a ideia da educação permanente é transferir a ideia centrada no ensino para a aprendizagem, ou seja, considerar a experiência de que aprende como principal instrumento para a sua formação.

No que se refere ao processo de reinvenção da organização escolar, Canário (2006) denuncia que as políticas educativas foram realizadas com metodologia vertical e autoritária, de forma analítica, fragmentada, não considerando o caráter global e sistêmico do sistema de ensino. O que se almeja nessa perspectiva é que a escola evolua na direção de um funcionamento como comunidades de aprendizagens, ou seja, que o trabalho do professor seja mais colaborativo, evitando a atitude de isolamento que tem caracterizado o trabalho do professor, em que cada um em sua disciplina e com sua sala se torna um mundo à parte, sem contato com os demais mundos. Atenta-se a isso o fato de o professor ser o principal inovador, buscando caminhos fecundos a partir do seu exercício profissional, da produção de mudanças com a dimensão da pesquisa e da formação. Portanto, a inovação em cada escola deverá ser um empreendimento de aprendizagem coletiva.

Para que a escola seja reinventada, necessariamente precisa de uma ação estratégica que incida em pontos críticos. Canário (2006) aponta três eixos estratégicos de intervenção:

1. Rompe com a ideia de que a inovação depende da existência de um acréscimo de recursos. A produção de mudanças qualitativa em um estabelecimento de ensino 
corresponde fundamentalmente à capacidade de organizar os recursos existentes de modo diferente.

2. Associa a produção de mudanças à ruptura com aquilo que tem sido as invariantes organizacionais da escola como os modos de gestão do tempo, do espaço, dos grupos de alunos etc. A intervenção de modos alternativos de gerir o tempo e os espaços, novas formas de articulação dos saberes disciplinares e modalidades de trabalho colaborativo dos professores são condições para fazer evoluir a escola de um sistema de repetição de informação para um sistema de produção de saberes, multiplicando as oportunidades de aprendizagem baseada em uma pedagogia ativa e interativa.

3. Consiste em conceber e praticar uma ação educativa globalizada, cuja referência seja um território educativo, ou seja, entendido num sentido triplo: primeiro, globalizando a ação educativa no próprio estabelecimento de ensino e promovendo uma multiplicidade diversa de oportunidade de aprendizagem; segundo, estabelecendo uma conexão privilegiada entre escola de uma mesma área e criando modalidades de colaboração e de utilização recíproca de recursos; e em terceiro, inserindo a ação da escola em um processo de globalização da ação educativa no quadro de um território, sob uma perspectiva de educação permanente e de desenvolvimento local integrado, Canário (2006).

O último elemento de ação para mudança da escola que aí está é construir uma nova legitimidade para ela, a qual consiste em linhas gerais na interpretação real da situação da crise da escola como a erosão dos fundamentos de uma visão otimista desta. Nesse sentido, superar a atual crise passa por recriar um novo sentido para o trabalho e para a vida escolar, o que para tal o autor apresenta três orientações fundamentais: “estimular gosto pelo ato intelectual de aprender, aprender pelo trabalho e exercer o direito à palavra" (CANÁRIO, 2006, p. 21).

A escola precisa se tornar um local onde se possa desenvolver e estimular o gosto pelo aprender, já que somos seres intrinsecamente curiosos e ávidos por aprender continuamente. Isso significa que a aprendizagem deve valer pelo seu valor de uso enquanto forma de conhecer e intervir no mundo e não pelo seu valor de troca como recompensas materiais e simbólicas. É na escola que se precisa aprender pelo trabalho, entendido como uma expressão de si. Enquanto continuarmos aprendendo para o trabalho, teremos uma forma alienada de viver o trabalho escolar. Dessa forma, precisamos que o aluno passe da condição de reprodutor a produtor de saberes. É necessário que a escola 
fomente o gosto pela política para que se viva verdadeiramente a democracia e que sejamos intolerantes com as injustiças e, principalmente, exerçamos o direito à palavra. Enfim, que os alunos aprendam a ser críticos, pensantes e atuantes.

\section{CONSIDERAÇÕES FINAIS}

Esta síntese da situação por que passa o sistema escolar e as mudanças pelas quais ele vem sofrendo desde sua origem, leva-nos a pensar as questões da educação de forma muito ampla, que perpassa obrigatoriamente pelas figuras do professor e do aluno como principais sujeitos desse processo, o que torna, por isso, um impedimento para uma análise mais geral, sendo necessário recortar elementos de análise e discussão, a fim de poder olhar mais cuidadosamente para uma das dimensões do processo educativo.

Dentro desse contexto de mudanças pelas quais vivem as sociedades, os quais envolvem diretamente a escola e todos que fazem parte dela, apontamos com maior ênfase a situação atual do professor, pois sobre ele recai grande parte dos problemas que acometem a escolarização atual. Esses problemas afetam diretamente a identidade profissional do professor, o que tem ocasionado, como já dito anteriormente, o mal-estar docente.

Diante de tudo que envolve esse mal-estar, temos consciência que as mudanças da atual conjuntura educacional exigem posturas, estratégias e ações complexas, amplas e variadas. Umas destas ações que necessitam de alto grau de reflexão para as adaptações a estas mudanças são, sem dúvida, pensar e direcionar as formações iniciais e continuadas para contribuir com processos formativos qualificados e consistentes.

A formação continuada precisa trazer para a discussão os elementos que envolvem os saberes e os fazeres dos professores, sem isso, dificilmente, as mudanças ocorrerão e, mais uma vez, o professor será o bode expiatório do conjunto de reformas que se empreende e se pretende empreender na educação, sem o devido sucesso que se esperava. Nesse sentido, tendo em vista o momento em que a educação escolar vive hoje é necessário e urgente um olhar mais sensível e atento para as várias mudanças que a sociedade vem sofrendo e que afeta diretamente a escola e seus partícipes mais diretos, neste caso, os professores e os alunos com seus desejos e saberes.

Recebido em: 30-05-2018 Aceito em: 17-07-2018 


\section{REFERÊNCIAS}

ARANHA, Maria L. de Arruda. Filosofia da educação. 2. Ed., São Paulo: Moderna, 1996.

ARANHA, Maria L. de Arruda. História da educação e da pedagogia: geral e Brasil. 3. Ed., São Paulo: Moderna, 2006.

BAUMAN, Zygmunt. Sobre educação e juventude. Tradução: Carlos Alberto Medeiros. Rio de Janeiro: Zahar, 2013.

BRANDÃO, Carlos Rodrigues. O que é educação. 2. Ed. São Paulo: Brasiliense, 1981 (coleção primeiros passos).

CANÁRIO, Rui. A escola tem futuro? das promessas as incertezas. Porto Alegre: Artmed, 2006.

CORTESÃO, Luiza. Ser professor: um ofício em risco de extinção?3. Ed. São Paulo: Cortez, 2011.

ESTEVE, JOSÉ M. Mudanças sociais e função docente. In: NÓVOA, A. (Org.). Profissão professor. Porto: Porto Ed., 1999. p. 93-124.

NÓVOA, Antonio. O passado e o presente dos professores. NÓVOA, A. (org.).Profissão professor. 2 ed. Porto: Porto Editora, 1999. p. 13-34. 